\title{
FRAGILIDADE AMBIENTAL DA BACIA HIDROGRÁFICA DO RIO SERIDÓ (RN/PB - BRASIL)
}

\section{ENVIRONMENTAL FRAGILITY OF THE RIVER BASIN OF SERIDÓ (RN/PB - BRAZIL)}

\author{
Manoel Cirício Pereira Neto \\ Departamento de Geografia, Universidade Federal do Ceará \\ Campus do Pici, Bloco 911. Fortaleza, Ceará, CEP: 60440-900, Brasil \\ Email: ciricio.ufrn@yahoo.com.br
}

Ermínio Fernandes

Departamento de Geografia, Universidade Federal do Rio Grande do Norte Campus Central, s/n. Natal, Rio Grande do Norte, CEP: 59078-900, Brasil

Email: erminio.fernandes@gmail.com

\begin{tabular}{l} 
Informações sobre o Artigo \\
\hline Data de Recebimento: \\
30/03/2015 \\
Data de Aprovação: \\
03/06/2015
\end{tabular}

Palavras-chave:

Ecodinâmica; Fragilidade;

Desertificação; Seridó.

\section{Keywords:}

Ecodinamyc; Fragility; Desertification; Seridó.

\section{Resumo:}

Este artigo apresenta uma análise da fragilidade ambiental da bacia hidrográfica do Rio Seridó, localizada entre os estados da Paraíba e do Rio Grande do Norte (Brasil), a fim de identificar áreas potencialmente instáveis. Este estudo encontrase apoiado na abordagem metodológica da Ecodinâmica de J. Tricart (1977) e em sua proposta de operacionalização defendida por J. Ross (1994), referente às unidades ecodinâmicas de instabilidade potencial e emergente com base nos índices de dissecação do relevo ou rugosidade topográfica e adaptada para o recorte espacial pesquisado. Os resultados revelam que, em uma perspectiva quantitativa sobre a análise da referida bacia hidrográfica, estes valores podem ser traduzidos em classes de fragilidade potencial em torno dos 2.613,0 $\mathrm{km}^{2}$ de fraca intensidade; $5.188,4 \mathrm{~km}^{2}$ de média intensidade; e dos $2.585,5 \mathrm{~km}^{2}$ de forte intensidade. No que diz respeito à fragilidade emergente, estes se aproximam dos 2.212,0 km² de fraca intensidade; 6.191,23 km² de média intensidade; e 2.062,34 $\mathrm{km}^{2}$ de forte intensidade. Os dados obtidos assumem importância fundamental para o planejamento territorial e ambiental da bacia hidrográfica, uma vez que foi possível ainda observar uma intrínseca associação dos municípios componentes do núcleo de desertificação do Seridó com as áreas de forte instabilidade/fragilidade ambiental.

\section{Abstract:}

This paper presents an analysis of the environmental fragility of the river basin Seridó, located between the states of Paraíba and Rio Grande do Norte (Brazil) in order to identify potentially unstable areas. This study is supported by the methodological approach of ecodynamic by J. Tricart (1977) and its proposed operation defended by J. Ross (1994), referring to the ecodinamics units of 
potential and emerging instability based on the relief dissection rates or topographical roughness and adapted to the spatial area searched. The results show that in a quantitative perspective on the analysis of that watershed, these values can be translated into potential fragility classes, around 2613.0 square kilometers of low intensity; 5188.4 square kilometers of medium intensity; and 2585.5 square kilometers at high intensity. With respect to the emerging fragility, they approach of 2212.0 square kilometers of low intensity; $6191.23 \mathrm{~km}^{2}$ of medium intensity; and 2062.34 square kilometers at high intensity. The data obtained have fundamental importance to the territorial and environmental planning watershed, since it was possible to observe an intrinsic association of municipalities components of Seridó desertification core with areas of strong instability/environmental fragility.

\section{Introdução}

A identificação dos processos e das diferentes fragilidades do meio natural, frente às pressões antrópicas que promovem degradação dos ambientes, é de fundamental importância para a conservação dos recursos naturais e para o estabelecimento de um planejamento ambiental e territorial eficiente. Segundo acrescenta Tricart e Killian (1979), seria, para fins de planejamento, uma enorme falta de perspectiva limitar-se a uma visão estática e descritiva do meio natural em uma espécie de inventário imutável.

Nesse contexto, o domínio semiárido das caatingas brasileiras, embora apresente uma aparente instabilidade ecodinâmica e crescentes níveis de degradação ambiental, é ainda atualmente descrito, por vezes, de modo superficial. Não obstante, trata-se de um dos semiáridos mais densamente povoados de todo o mundo envolto por uma complexidade de mosaicos com características climáticas, ecológicas, pedológicas e hidrológicas distintas (AB'SABER, 1974, 2007; ANDRADE-LIMA, 1981; DUQUE, 1953, 1964).

É com base nesses preceitos e contextualização, diante das lacunas então existentes sobre essa problemática e sobre o recorte espacial proposto que se aponta a bacia hidrográfica do Rio Seridó (RN/PB) como recorte e unidade de análise (ver Figura 1). Essa escolha justifica-se ainda por essa área compreender um dos quatro núcleos de desertificação brasileiro, abrangendo as regiões do Seridó potiguar e paraibano. Nesse sentido, acrescenta-se que a desertificação, segundo Herrmann e Hutchinson (2005), é ainda atualmente bastante debatida acerca de sua existência, definição conceitual e formas de avaliação e análise.

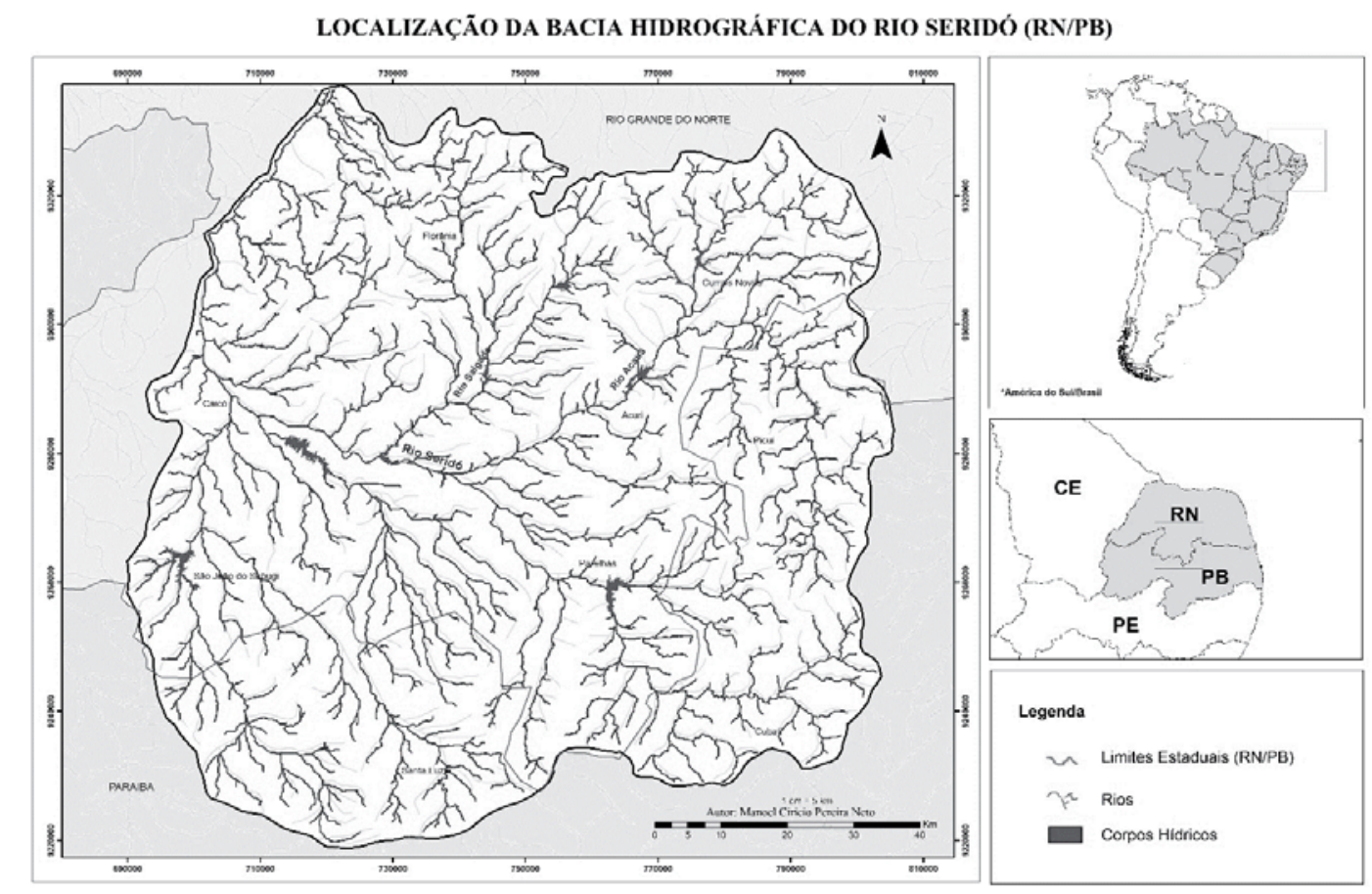

Fonte: elaborado pelos autores

Figura 1 - Mapa de Localização da bacia hidrográfica do Rio Seridó (RN/PB) 
O recorte espacial referente à bacia hidrográfica destaca-se por ser também uma unidade natural básica para o planejamento em que se encontram condições favoráveis para uma avaliação de forma integrada das ações humanas e suas consequências sobre o equilíbrio dinâmico, juntamente ao restante do sistema ambiental (BERTONI e LOMBARDI NETO, 2012; BOTELHO e SILVA, 2011; COELLHO NETO, 2007; MOLLE, 2006).

Em termos gerais, a bacia hidrográfica do Rio Seridó, principal sub-bacia do Piranhas-Assu, encontra-se localizada entre as regiões do Seridó potiguar e paraibano. No estado potiguar, a bacia hidrográfica abrange 20 municípios e, no estado paraibano, outros 13 municípios, totalizando uma área total de aproximadamente $10.386 \mathrm{Km}^{2}$.

Destarte, esta pesquisa objetiva analisar a fragilidade ambiental da bacia hidrográfica do Rio Seridó (RN/PB), possibilitando a identificação de áreas potencialmente instáveis. A fragilidade, nesse caso, encontra-se associada a uma maior ou menor instabilidade do sistema natural (fragilidade potencial), em relação à ocorrência dos diferentes processos erosivos, por vezes, ainda intensificados pelo estabelecimento da ação humana, de modo nesse trabalho analisado através da cobertura vegetal (fragilidade emergente).

Conforme acrescenta Ross (1994), a fragilidade dos ambientes naturais face às intervenções humanas será, portanto, maior ou menor em função de suas características genéticas. A princípio, segundo ressalta esse pesquisador (op. cit.), os sistemas naturais revelam-se em um estado de equilíbrio dinâmico. Para Christofoletti (1974, p. 135), essa é uma condição indicadora de que "em um sistema erosivo todos os elementos da topografia estão mutuamente ajustados, de modo que eles se modificam na mesma proporção", refletindo, segundo acrescenta Howard (1988), em diferentes tipos ou níveis de estabilidade.

\section{Metodologia}

É utilizado, nesta pesquisa, o enfoque dado à Ecodinâmica apresentada por Tricart (1977), e a proposta de sua operacionalização utilizada por Ross (1994), de modo ainda adaptada para a área de estudo. Essa teoria oferece suporte para a classificação de unidades em níveis de estabilidade, os chamados meios estáveis, meios intergrades e meios instáveis. Segundo ressalta o próprio Tricart (1977), a Ecodinâmica, para efeitos de contextualização, encontra-se integrada ao conceito de Ecossistema, fundamentando-se, sobretudo, sobre as relações mútuas entre os diversos componentes, a sua dinâmica e os fluxos de matéria/energia no ambiente com base, principalmente, no balanço entre pedogênese/ morfogênese.

Os dados obtidos com as técnicas do geoprocessamento foram, posteriormente, analisados com as observações em campo, juntamente aos possíveis indicadores geoambientais de áreas de uma maior ou menor estabilidade/instabilidade. Todas as etapas encontram-se diretamente organizadas de acordo com Libaut (1971), acerca dos quatros níveis da pesquisa geográfica. Por último, juntamente a construção de um SIG (Sistema de Informação Geográfica), verificou-se a inserção e análise de várias bases cartográficas e imagens disponíveis, juntamente à confecção de dados primários, a saber:

1. Dissecação do Relevo ou Rugosidade Topográfica: a identificação da dissecação do relevo foi elaborada de acordo com a proposta de Sampaio e Augustin (2008), através dos índices de concentração da rugosidade (ICR), trabalhadas no programa ArcGis 9.3 (ESRI), conforme a proposta de Ross (1994).

2. Cobertura pedológica: os dados referentes aos solos da área de estudo foram organizados através das informações e mapeamentos apresentados, a saber: a) Folha Natal/Jaguaribe na escala 1:1.000.000, do projeto RADAMBRASIL (1981); b) dos estudos de Jacomine et al. (1971, 1972), na escala de 1:500.000; c) dos estudos realizados por Silva et al. (2001), da Folha Jardim do Seridó na escala 1:100.000; d) do reconhecimento fotogeológico das folhas de Currais Novos, Caicó e Orós em escala 1:100.000, realizado por Morais e Barros (1960). Esses dados foram compilados e trabalhados no ArcGis 9.3 (ESRI), em uma escala aproximada de 1:250.000. Com relação às classes de fragilidade, relacionadas as associações de solos, essas estão organizadas de acordo com as proposições de Gomes et al. (2005), a saber: (1) de menor instabilidade, com destaque aos Latossolos e Argissolos; (2) média instabilidade, os Luvissolos Crômicos, Planossolos Natrícos e os Neossolos Flúvicos; e, (3) de alta instabilidade, as classes de Neossolos Litólicos e Neossolos Regolíticos.

3. Dados pluviométricos: foi elaborada a média de precipitação anual referente à série histórica de 30 anos 
(1961-1990), cujos dados foram levantados, a partir de: a) Molinier et al. (1994); b) Medeiros et al. (2005) e; c) Valadão et al. (2010). Esse conjunto de dados foi tratado espacialmente junto ao programa SURFER 10 (Golden Software), cuja interpolação foi realizada através do método de Krigagem, responsável pela estimação espacial dos dados, e obtenção da variação pluviométrica sobre o recorte da pesquisa. É interessante ressaltar que foram levantados dados de 30 postos pluviométricos distribuídos dentro da bacia hidrográfica.

4. Cobertura vegetal: o estudo da cobertura vegetal foi realizado mediante a fusão e interpretação de imagens multiespectrais (órbitas/pontos 215/064 e 215/065) do satélite Landsat5 TM (Thematic Mapper), com resolução espacial de $30 \mathrm{~m}$ x $30 \mathrm{~m}$, datadas do dia 24 de maio de 2010. Para a identificação do grau de conservação ou de degradação da cobertura vegetal, foi utilizado o Índice de Vegetação da Diferença Normalizada (NDVI), através do software ARCGIS 9.3. Esse tratamento permitiu a classificação da cobertura vegetal, mediante a adaptação da pesquisa realizada por Alves $(2007,2009)$. Destacam-se as seguintes classes: (1) fragilidade emergente fraca (Caatinga arbórea-arbustiva densa e Caatinga arbustiva-arbórea densa); (2) fragilidade emergente média (Caatinga arbustiva-densa); e (3) fragilidade emergente forte (solo exposto). Esses elementos vinculados à classe de fragilidade emergente forte, apesar de se apresentarem aparentemente distintos, possuem em comum, no contexto proposto à atribuição da instabilidade, a presença de dinâmicas relacionadas à forte instabilidade frente às ações antrópicas. No entanto, é ainda interessante destacar que a cobertura vegetal foi utilizada como um importante indicador de degradação do ambiente, tendo em vista o contexto socioambiental da região do Seridó e o uso desse indicador nos estudos de Erhart para análise de bio-resistasia, e de Tricart (1977) na análise ecodinâmica.

Com base nesses dados, procedeu-se, então, à análise dos fatores e das unidades ecodinâmicas através da álgebra de mapas com o auxílio do software ARCGIS 9.3 (ESRI). Sobre essa contextualização, seguiuse a lógica de Ross (1994) de modo a hierarquizar as variáveis analisadas (dissecação, solos, pluviosidade e vegetação) e as unidades ecodinâmicas correspondentes com relação ao grau de fragilidade, representando-as de forma adaptada ao recorte espacial por algarismos que vão de muito fraca (1), média (2), até muito forte (3).
Da combinação desses parâmetros em códigos (ex: 1111, 1233, 3333), segundo acrescenta Spörl (2001), é então possível hierarquizar os diferentes graus de fragilidade. Igualmente interessante, segundo os procedimentos de Ross (1994) e Spörl e Ross (2004), o primeiro dígito, correspondente ao índice de dissecação do relevo, é sempre quem vai determinar o grau de fragilidade potencial de cada área. As demais variáveis irão apenas definir uma hierarquização através de seus coeficientes de fragilidade, sendo que a variável cobertura vegetal, correspondente ao $4^{\circ}$ dígito, irá identificar as áreas onde o equilíbrio dinâmico foi rompido de modo associado à instabilidade de caráter emergente.

Todas as informações obtidas na elaboração dos mapeamentos acerca das fragilidades foram verificadas em associação com diversas viagens de campo ao longo da bacia hidrográfica, de modo a identificar possíveis incongruências do modelo adotado.

\section{Análise Síntese de Fragilidade da Bacia Hidrográ- fica do Rio Seridó (RN/PB - Brasil)}

Em termos gerais, no que diz respeito à análise da fragilidade do meio, conforme ressalta Ross (1994), esta perpassa obrigatoriamente pelo inventário do quadro natural à medida que os dados são confrontados e posteriormente avaliados integradamente. Desse modo, de acordo com a proposta de analise adotada nesta pesquisa, o estudo de áreas potencialmente frágeis envolve, portanto, a identificação e combinação de variáveis distintas (relevo-solo-pluviosidade), de modo ainda combinadas com uma instabilidade emergente, decorrente do grau de conservação ou de degradação da cobertura vegetal existente.

No que se refere à dissecação do relevo, por exemplo, essa se encontra intimamente atrelada ao fornecimento de importantes subsídios para a identificação da energia potencial responsável pela intensificação do escoamento hídrico superficial e da instabilidade do meio.

Com relação às classes de solos, estas aparecem como sendo de fundamental importância para a compreensão dos variados processos e/ou fenômenos erosivos. Segundo Bigarella (2003), a susceptibilidade à erosão nesse caso torna-se ainda intensificada em função da declividade do terreno, das características do perfil do solo e das condições climáticas. 


\section{Fragilidade Ambiental da Bacia Hidrográfica do Rio Seridó (RN/PP - Brasil)}

A pluviosidade, por sua vez, apresenta-se como um importante fator para a análise da fragilidade, por meio da quantidade e da concentração de água disponível para o escoamento hídrico superficial em um determinado período de tempo. Neste sentido, quanto maior é a pluviosidade média anual e curta é a duração do período chuvoso, maior será a capacidade e potencial de erosão (CREPANI, 2001; SPÖRL e ROSS, 2004).
Nesse contexto, sobre a bacia hidrográfica do Rio Seridó (RN/PB), em termos gerais, é interessante destacar a análise setorial dos elementos envolvidos junto à identificação da dissecação do relevo, classes de solos e pluviosidade (ver Figura 2), para a posterior integração das variáveis. Esse conjunto de informações tende, portanto, a estabelecer certa complexidade perante à análise das unidades ecodinâmicas, segundo o grau de estabilidade.
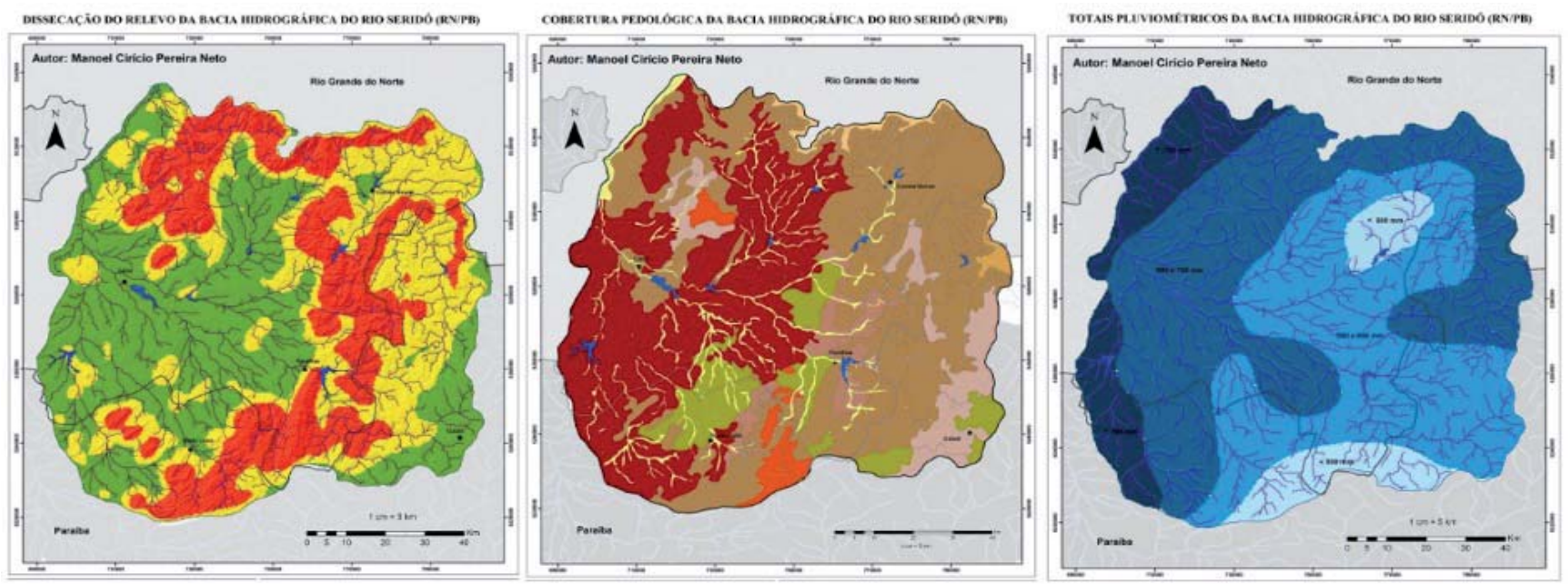

Fonte: acervo dos autores

Figura 2 - Aspectos relacionados à análise da fragilidade/instabilidade potencial: rugosidade topográfica ou dissecação do relevo; classes de solos e distribuição espacial da pluviosidade.

Destarte, a análise sobre a organização do conjunto decorrente das relações entre os elementos confere o estado e a função do todo. Ou seja, o esforço sistêmico, conforme ressalta Christofoletti (1999, p. 04), é o de entender como as partes estão integradas em uma totalidade, “[...] compreender o conjunto mais do que suas partes”. Nesse caso, a identificação da fragilidade do meio, por meio de unidades ecodinâmicas, tende a fornecer, portanto, importantes subsídios ao entendimento da bacia hidrográfica como um verdadeiro sistema.

\subsection{Fragilidade Potencial com Base na Proposta de Jurandyr Ross (1994)}

De início, entende-se por fragilidade potencial a distância do qual o sistema natural encontra-se de uma possível instabilidade. Esta última, por sua vez, está intimamente relacionada ao grau o qual o escoamento hídrico superficial e concentrado possui mediante os processos erosivos, entre outros processos semelhantes.
Os resultados revelam que, em uma perspectiva quantitativa sobre a análise da referida bacia hidrográfica, esses valores podem ser traduzidos em classes de fragilidade potencial em torno dos $2.613,0 \mathrm{~km}^{2}$ de fraca intensidade; $5.188,4 \mathrm{~km}^{2}$ de média intensidade; e dos $2.585,5 \mathrm{~km}^{2}$ de forte intensidade (ver Figura 3). Conforme se pode verificar com os valores obtidos, a bacia hidrográfica em questão apresenta, aproximadamente, metade de sua extensão (50,0\%) envolta pela unidade ecodinâmica de instabilidade potencial de média intensidade, seguida, respectivamente, pelas classes de fraca intensidade (26,0\%) e de forte intensidade (24,0\%). Essas classes serão descritas e caracterizadas logo a seguir:

I) Classe de instabilidade potencial de fraca intensidade

A fragilidade potencial de fraca instabilidade compreende 2.613,0 km², ou cerca de 26,0\% da bacia hidrográfica do Rio Seridó. Esta abrange grande parte da Depressão Sertaneja, com a predominância de baixas amplitudes altimétricas, mediante a presença de um 


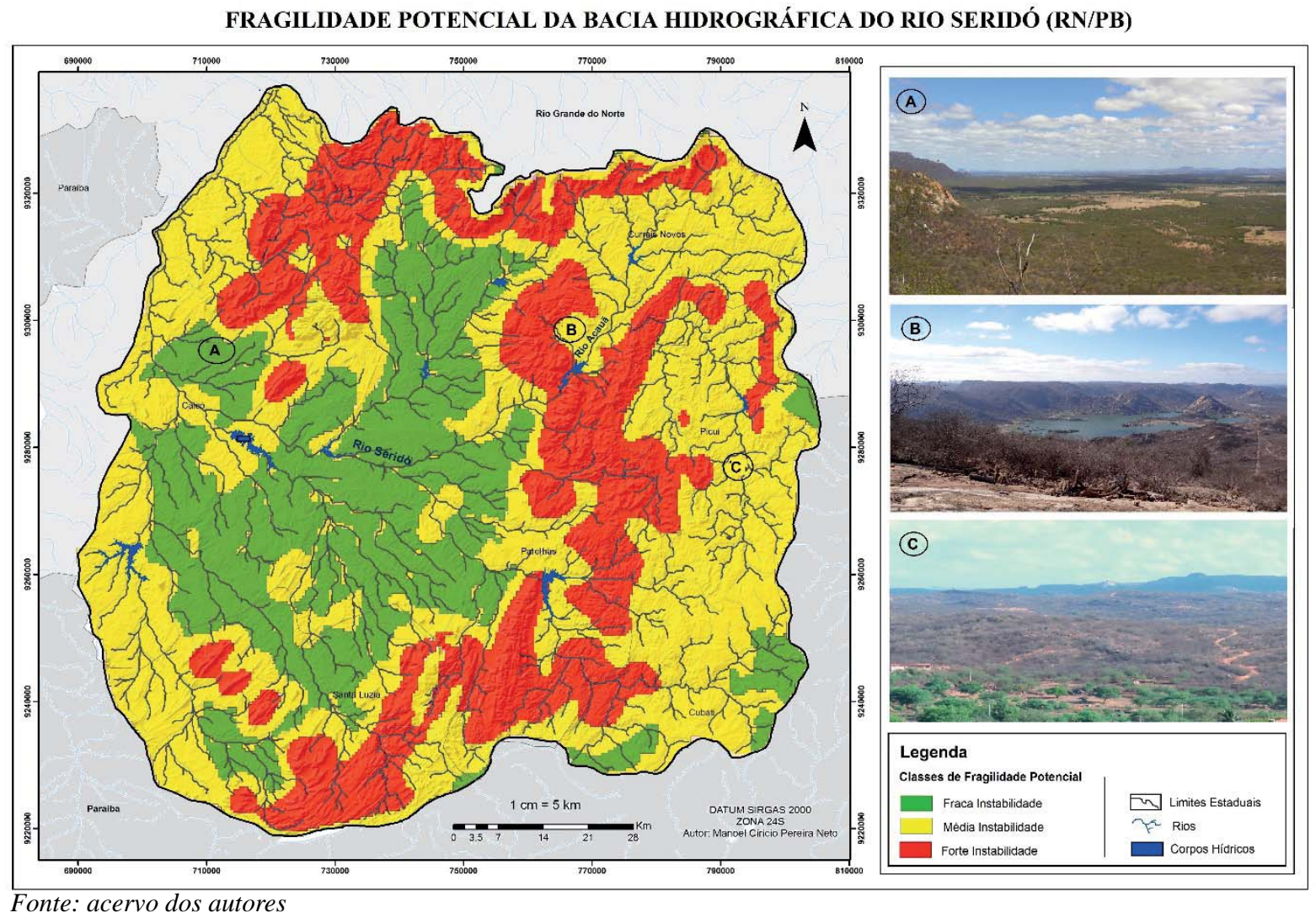

Figura 3 - Fragilidade potencial da bacia hidrográfica do Rio Seridó (RN/PB), com destaque para as fotos, como exemplo de áreas de instabilidade: (a) fraca-depressão Sertaneja nas proximidades de Caicó/RN); (b) média-áreas aplainadas do Planalto da Borborema em Picuí/PB; e (c) forte - maciços residuais do Planalto da Borborema em Acari/RN.

relevo suave-ondulado e solos relacionados à classe de média fragilidade à erosão, no caso dos Luvissolos Crômicos, Planossolos Natrícos e Neossolos Regolíticos. Sobre a classe de fragilidade desses solos, descreve-se como parâmetro o grau de desenvolvimento e amadurecimento desses, então relacionados com o contexto da bacia hidrográfica em questão.

Atenta-se ainda para o fato de que essas áreas, apesar de apresentarem associações de solos que estão na classe de média fragilidade, as condições de dissecação do relevo, relacionadas à Depressão Sertaneja e com características suave-ondulado, aparecem como as áreas de menor instabilidade potencial.

Nesse caso, como o relevo possui um maior grau de influência no estabelecimento da fragilidade potencial, a área indicada acaba destacando-se como de instabilidade potencial de fraca intensidade, de modo que as condições morfológicas do relevo conseguem equilibrar as características de relativa fragilidade dos solos.
II) Classe de instabilidade potencial de média intensidade

A fragilidade potencial de média intensidade abrange aproximados 5.188,4 $\mathrm{km}^{2}$, recobrindo 50,0\% da área da bacia hidrográfica estudada. Compreende algumas áreas da Depressão Sertaneja, de acordo com os diferentes níveis de pediplanação (Pd1 e Pd1), ainda sobre grande parte desde nordeste até sudeste da bacia hidrográfica, sobre o Planalto da Borborema com relevo suave-ondulado a ondulado e ainda as planícies fluviais como áreas de dinâmica relativamente instável. É interessante ressaltar a existência de uma área que vai desde as proximidades do município de São Mamede/ PB, passando por São João do Sabugi até o município de Jucurutu, no estado potiguar - correspondente ao sudoeste até o noroeste da respectiva bacia hidrográfica. Esta, apesar de não apresentar um relevo fortemente dissecado, possui as maiores taxas de pluviosidade média anual, dispondo de grande energia cinética para a intensificação dos processos de maior instabilidade. 
III) Classe de instabilidade potencial de forte intensidade

A fragilidade potencial de forte intensidade corresponde a uma extensão de $2.585,5 \mathrm{~km}^{2}$ ou cerca de $24,0 \%$ da área total. O relevo aparece, em termos gerais, como sendo vigorosamente dissecado caracterizado por rebordos abruptos e sinuosos e presença de vertentes com grande declividade. Esse contexto é ainda de modo intensificado pela concomitante presença de solos altamente susceptíveis à erosão com destaque para ocorrência dos Neossolos Litólicos. São exemplos dessas áreas o complexo Acari-Carnaúba dos Dantas, as escarpas da Serra de Santana, relevos residuais como cristas e inselbergs, entre outros.

Este contexto favorece que, diante da presença de chuvas com potencial erosivo, a tênue camada pedológica seja mais facilmente carreada vertente abaixo, dificultando ou impedindo a regeneração da cobertura vegetal e a estabilidade do sistema. Igualmente importante, realiza-se a intensificação dos processos erosivos entre diversos outros processos de instabilidade.

Destarte, observa-se, através da análise da dissecação do relevo associada à cobertura vegetal e à espacialização dos totais pluviométricos, que o parâmetro geomorfológico mostra-se de grande relevância à análise ecodinâmica e ao entendimento da fragilidade potencial mediante a indicação das áreas de maior ou menor instabilidade. Sobre essa assertiva, é interessante ainda destacar, segundo acrescenta Tricart e Killian (1979), que os fenômenos estudados pela geomorfologia se inserem na análise ecodinâmica de duas maneiras diferentes: desempenham uma importante função na dinâmica geral dos sistemas naturais pelos fluxos de matéria que, por sua vez, provocam diferentes modificações na superfície terrestre e; aderem ao longo do tempo certas características importantes do meio natural que são os parâmetros, os aspectos e suas diferentes manifestações.

\subsection{Fragilidade Emergente Mediante a Análise da Cobertura Vegetal}

No que diz respeito à análise da fragilidade emergente, segundo a proposta de Ross $(1990,1994)$, essa pode ser entendida como sendo aquela na qual as ações humanas desestabilizaram o equilíbrio dinâmico do sistema ou mesmo à própria distância para que essa ação decorra mediante o grau de proteção dos solos exercido pela cobertura vegetal. A retirada e/ou proteção da vegetação tende a se constituir, nesse sentido, em um ótimo indicador para a identificação das áreas mais ou menos instáveis.

Em termos gerais, no que diz respeito à fragilidade emergente sobre a extensão da bacia hidrográfica do Rio Seridó, essa se aproxima quantitativamente dos 2.212,0 $\mathrm{km}^{2}$ de fraca intensidade, $6.191,23 \mathrm{~km}^{2}$ de média intensidade e $2.062,34 \mathrm{~km}^{2}$ de forte intensidade. Conforme os valores obtidos, verifica-se que eles representam a predominância das áreas referentes à unidade ecodinâmica de instabilidade potencial de média intensidade com aproximadamente 59,0\% da área pesquisada. Seguida, respectivamente, pelas classes de fraca intensidade com $21,0 \%$ e das áreas de forte intensidade, em torno dos 20,0\% da bacia hidrográfica do Rio Seridó. Essas classes estão descritas e caracterizadas logo a seguir (ver Figura 4).

I) Classe de instabilidade emergente de fraca intensidade

A fragilidade emergente fraca abrange uma área de $2.212,0 \mathrm{~km}^{2}$, ou cerca de $21 \%$ do total. Envolve basicamente áreas caracterizadas por uma vegetação de caatinga arbórea-arbustiva densa e/ou de caatinga arbustiva-arbórea densa pouco degradada ou com vegetação primária. Encontram-se distribuídas geograficamente pelas extensões topograficamente de relativa dissecação que tende a dificultar o acesso para o desenvolvimento de atividades humanas. São áreas como as escarpas fortemente dissecadas da Serra de Santana do complexo serrano nas proximidades do município de Acari/RN, alguns relevos residuais, entre diversas outras. Segundo acrescentam Pereira Neto e Silva (2012), essas áreas se constituem em verdadeiros refúgios da biodiversidade regional.

É interessante ressaltar a importância de conservação dessas áreas, uma vez que diante da forte fragilidade potencial (inerente às condições naturais), o estabelecimento das ações humanas de degradação tenderia a tornar essas áreas de grande fragilidade ambiental, entendida como produto-síntese. Entretanto, conforme é destacado nesse trabalho, apesar de possuírem instabilidade potencial, essa é ainda de certo modo equilibrada com uma cobertura vegetal densa que dificulta a dinâmica acelerada dos fluxos de matéria e energia.

Sobre esse contexto, Tricart (1976) ainda acrescenta o fato de que uma cobertura vegetal suficientemente espessa pode manter os declives muito acentuados em 
FRAGILIDADE EMERGENTE DA BACIA HIDROGRÁFICA DO RIO SERIDÓ (RN/PB)

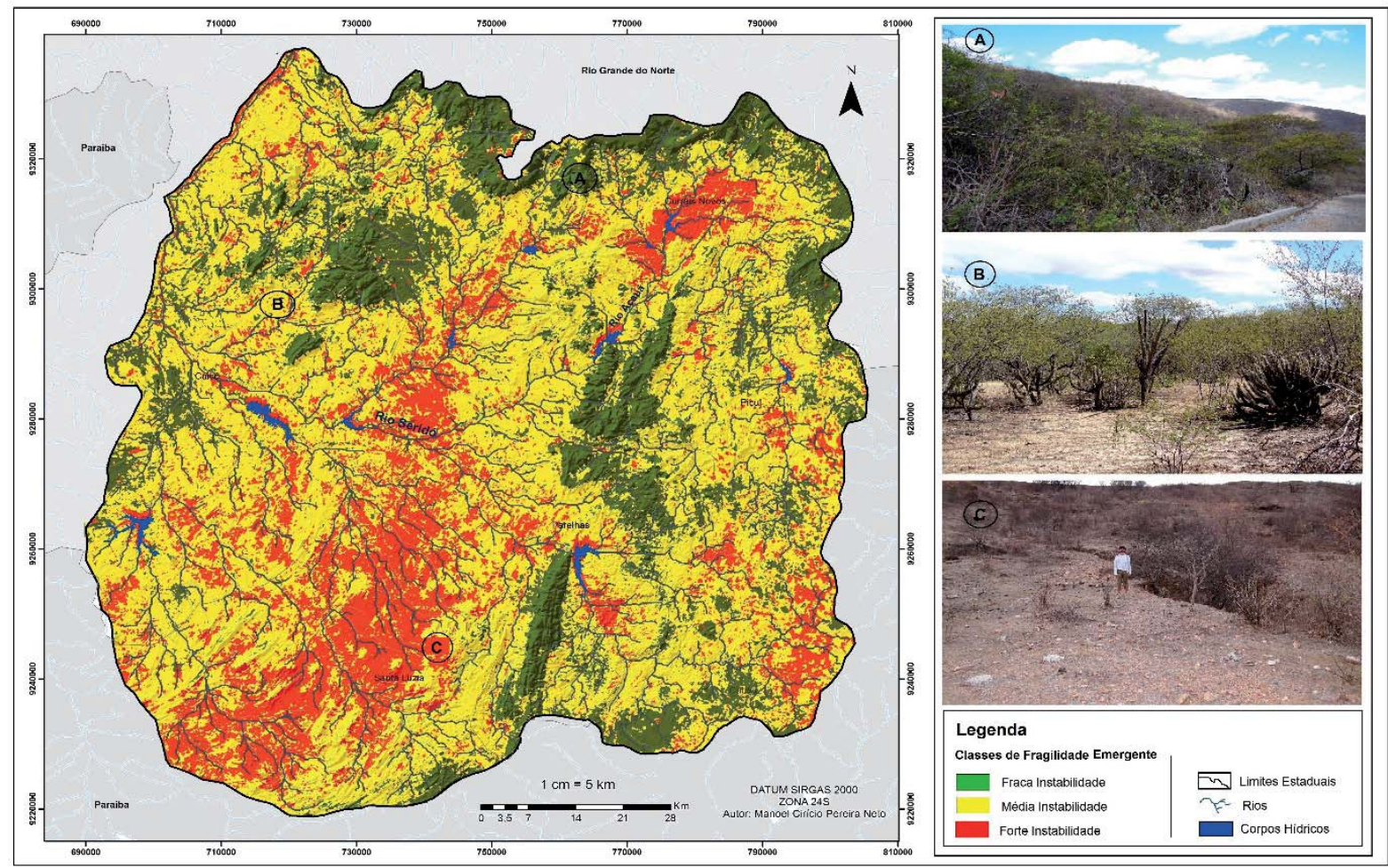

Fonte: acervo dos autores

Figura 4 - Fragilidade emergente da bacia hidrográfica do Rio Seridó (RN/PB) com destaque para as áreas de instabilidade: (a) fraca - caatinga densa das escapas da Serra de Santana, proximidade de São Vicente/RN; (b) média - caatinga espaçada sobre a Depressão Sertaneja, em Caicó/RN; e (c) forte - solo exposto com forte presença de ravinamentos em Parelhas/RN.

uma relativa estabilidade. Esta ameniza ou impede o fluxo hídrico superficial e, em seguida, o carreamento de detritos que favorece, por sua vez, a restauração da vegetação, reconstituição do solo e, com estes, o processo de pedogênese e, consequentemente, a estabilidade do meio analisado.

II) Classe de instabilidade emergente de média intensidade

A fragilidade emergente média compreende a maior parte da área analisada com uma extensão de $6.191,23 \mathrm{~km}^{2}$, equivalente a 59,0\% da área total. Esse contexto abrange ora parte da Depressão Sertaneja, ora também os relevos suave-ondulados do Planalto da Borborema. Nesse caso, o relevo torna-se um elemento que tende a favorecer o desenvolvimento das ações humanas regionais, como o desenvolvimento das atividades agropecuaristas. É um dado que, por sua vez, tende a explicar o grau de relativa degradação dessa vegetação de caatinga. Essa envolve a cobertura vegetal caracterizada como sendo de Caatinga arbustiva densa, por vezes com o predomínio de uma só espécie (a Jurema-Preta - Mimosa tenuiflora [Wild]), devido ao caráter de pioneirismo. Esse cenário caracteriza-se, portanto, por um tênue limiar ora com o favorecimento da pedogênese, ora com o processo de morfogênese.

III) Classe de instabilidade emergente de forte intensidade

A fragilidade emergente forte abrange aproximados $2.062,34 \mathrm{~km}^{2}$, o que compreende cerca de $20,0 \%$ da extensão total. Esta é caracterizada mediante a presença de Caatinga antropizada, entendida aqui como sendo aquela com intensas marcas de degradação.

É apresentada em termos gerais pela vegetação de porte arbóreo ou arbustivo de modo espaçado ou ainda através da exposição do solo e/ou pelos reservatórios hídricos. Sobre essa assertiva, ressalta a presença de relevos suaves ondulados da Depressão Sertaneja e presença de solos relativamente de grande fertilidade como no caso dos Luvissolos Cromicos. Esse contexto 
favoreceu ao longo dos anos o desenvolvimento de uma pecuária extensiva, resultando no cenário atual de grande degradação da cobertura vegetal.

As áreas com alta fragilidade emergente representam, portanto, os locais de maior pressão ambiental, então indicados neste estudo por meio da conservação ou degradação da cobertura vegetal sobre a extensão da área desta pesquisa, uma vez que interferem nos processos e engendramento do sistema natural. Sobre as atividades antrópicas exercidas nessa classe de fragilidade, destacam-se atualmente à retirada de lenha e de argila para o desenvolvimento da indústria ceramista. No Seridó potiguar, segundo acrescenta Azevedo (2005), são cerca de 150 unidades produtoras de cerâmica vermelha.

\subsection{Fragilidade Ambiental Síntese e o Núcleo de Desertificação do Seridó (RN/PB)}

A análise da fragilidade ambiental, relacionada à intensificação de processos erosivos e forte dinâmica ambiental, apresenta-se como um produto síntese dos dados e das informações obtidas mediante a combinação das unidades ecodinâmicas de fragilidade potencial e de fragilidade emergente. Esta análise reflete, pois, as áreas em que a instabilidade potencial do sistema natural foi sobremaneira afetada por uma pressão emergente, de modo a dificultar o restabelecimento de sua estabilidade.

Sobre a área de pesquisa, os valores revelam que aproximados 150,0 km² são caracterizados como potenciais unidades ecodinâmicas estáveis, $8.137,2$ km² como sendo unidades ecodinâmicas intergrades e, em torno dos 2.099,1 km², aquelas identificadas como unidades ecodinâmicas instáveis (ver Figura 5).

Em termos gerais, esse é um contexto que chama a atenção pela diminuta área caracterizada como sendo uma unidade ecodinâmica estável com apenas 150,0km² de extensão, ou cerca de 2,0\% da área total; em contraposição à predominância das unidades ecodinâmicas integrades (78,0\%), seguidas das unidades ecodinâmicas instáveis (20,0\%), respectivamente. São dados que suscitam interessantes questionamentos sobre as áreas de forte instabilidade ecodinâmica em associação ao processo de desertificação.

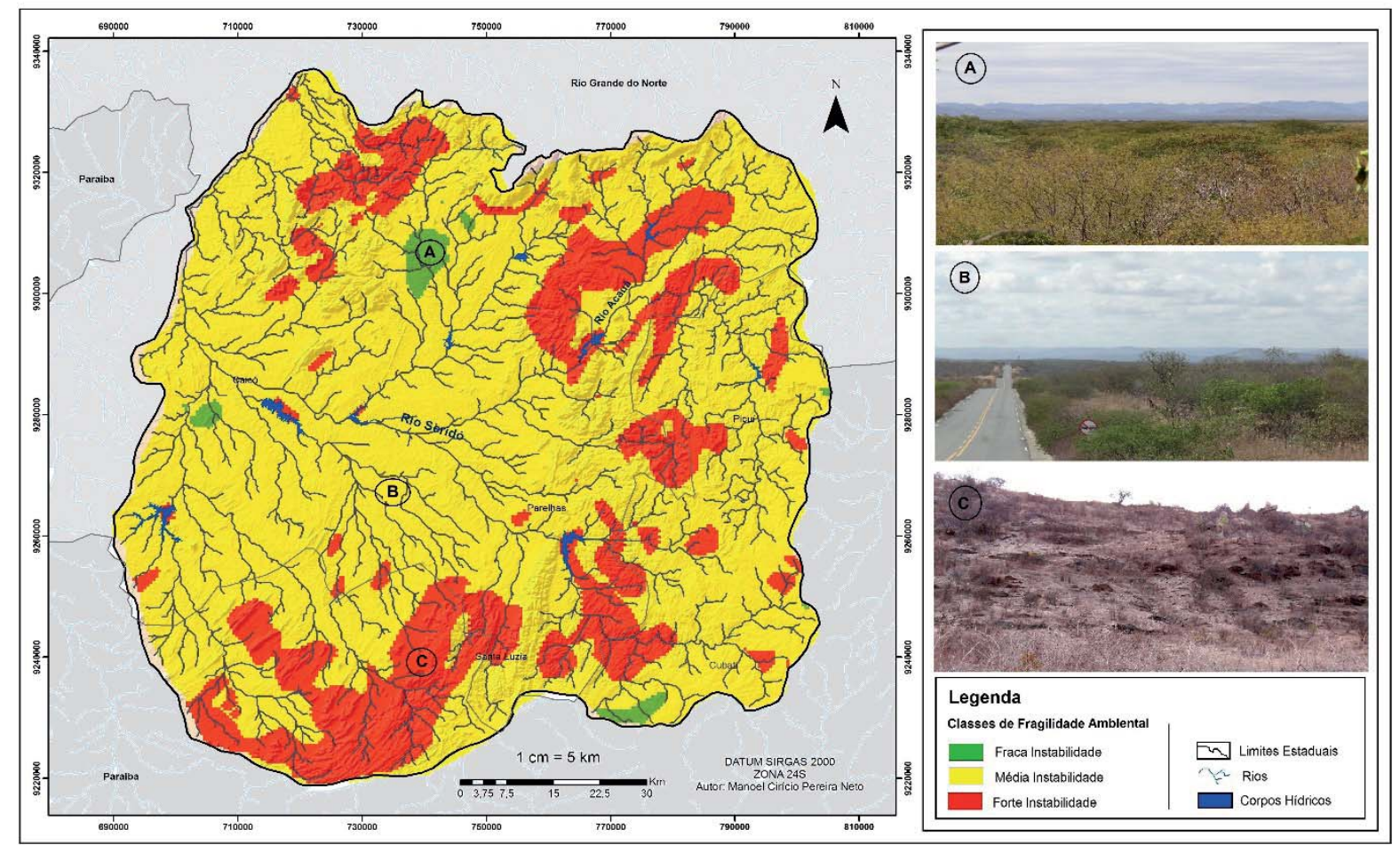

Fonte: acervo dos autores

Figura 5 - Fragilidade ambiental síntese da bacia hidrográfica do Rio Seridó (RN/PB) com destaque para as áreas de instabilidade: (a) fraca - caatinga densa das escapas da Serra de Santana, proximidade de São Vicente/RN; (b) média - caatinga espaçada sobre a Depressão Sertaneja em Caicó/RN; e (c) forte - solo exposto com grande presença de ravinamentos, em Parelhas/RN. 
I) Classe referente às unidades ecodinâmicas estáveis

Essa unidade se apresenta através de pequenas manchas sobre a área da pesquisa, abrangendo apenas uma extensão de aproximados $150,0 \mathrm{Km}^{2}$, ou cerca de 2,0\% da área de estudo. São áreas que conceitualmente apresentam uma relativa estabilidade com dinâmica relativamente lenta. Em termos gerais, apresentam relevo sem grande dissecação, relativamente plano e/ou suave-ondulado com solos bem desenvolvidos e baixa susceptibilidade à erosão sem grandes índices pluviométricos médios anuais, juntamente a uma vegetação de caatinga arbórea-arbustiva ou arbustiva-arbórea.

Corresponderia às áreas de biostasia onde os elementos do potencial ecológico e da exploração biológica estão em equilíbrio (SOUZA e OLIVEIRA, 2011). São áreas clímax que devem suscitar importantes pesquisas futuras por resguardar possivelmente um importante banco genético sobre o contexto geoambiental de desertificação junto à região do Seridó.

\section{II) Classe referente às unidades ecodinâmicas intergrades}

A área caracterizada como referente às unidades ecodinâmicas intergrades compreende uma extensão em torno dos $8.137,2 \mathrm{~km}^{2}$, o que corresponde a aproximados $78,0 \%$. Diz respeito à grande parte do recorte espacial desta pesquisa, apresentando-se como a classe predominante sobre a bacia hidrográfica em questão.

Destaca-se uma considerável área da Depressão Sertaneja com características de fraca-dissecação dispostas em um relevo suave-ondulado em associação aos solos medianamente susceptíveis à erosão e à presença de uma vegetação de caatinga arbustiva-densa. Nesse caso, apresentam-se como áreas que ora predominam o desenvolvimento da morfogênese, ora da pedogênese. São também caracterizadas pela transição ecodinâmica as áreas mais aplainadas do Planalto da Borborema, à leste da referida bacia hidrográfica, que possuem vegetação de caatinga mais densa ainda de modo conservada.

Além disso, são exemplos dessa contextualização algumas áreas correspondentes às escarpas da Serra de Santana, no estado potiguar, onde a instabilidade morfodinâmica (potencial), decorrente de um relevo dissecado, é de sobremaneira ainda mantida em relativa estabilidade pela presença de uma cobertura vegetal densa ainda bastante conservada.
III) Classe referente às unidades ecodinâmicas instáveis

As unidades ecodinâmicas instáveis compreendem uma extensão em torno dos 2099,1 $\mathrm{km}^{2}$ ou 20,0\% da bacia hidrográfica do Rio Seridó. Estas se encontram distribuídas através de algumas manchas de considerável extensão, especialmente entre os contrafortes da região geomorfológica do Planalto da Borborema com a Depressão Sertaneja.

São áreas que podem ser caracterizadas pela forte instabilidade ecodinâmica (fragilidade emergente), de modo a exercer considerável pressão sobre as áreas potencialmente instáveis (fragilidade potencial). Destaca-se nessas unidades ecodinâmicas a predominância de relevos fortemente dissecados associados à ocorrência de Neossolos Litólicos ou à presença de solos expostos e à ausência da cobertura vegetal.

Nesta etapa da pesquisa, aparece uma importante informação secundária e de fundamental importância como fonte subsidiária da análise. As áreas identificadas como unidades ecodinâmicas instáveis, frente ao contexto apresentado, aparecem estritamente relacionadas com os municípios componentes do Núcleo de Desertificação do Seridó (PEREIRA NETO, 2013). De modo a ainda incluir, inclusive outros municípios não citados em trabalhos oficiais anteriores (CARVALHO et al., 2000; RIO GRANDE DO NORTE, 2000; BRASIL, 2004), como no caso do município de Florânia, no estado do Rio Grande do Norte, que encontra-se inserido sobre uma considerável mancha de forte instabilidade ao noroeste da bacia hidrográfica do Rio Seridó (RN/ $\mathrm{PB})$, conforme observado neste trabalho.

Segundo a Convenção Internacional de Combate à Desertificação e à Seca (UNCCD), o fenômeno da desertificação pode ser conceituado como sendo o processo de degradação das terras em áreas áridas, semiáridas e sub-úmidas secas, resultante de vários fatores, incluindo variações climáticas e atividades humanas de sobre-exploração. A degradação de terras apresenta-se, nesse caso, como sendo a redução ou perda da fertilidade e da produtividade biológica ou econômica das terras áridas (BRASIL, 2004).

Conforme é ressaltado por Hare et al. (1977), esse fenômeno pode ser entendido através do declínio duradouro da atividade biológica, de modo que esse não é, um fenômeno instantâneo, mas a complementação do processo de degradação da vegetação e do solo. 
Ainda segundo a referida autora (op. cit.), inicia-se, em geral, nas zonas naturalmente frágeis e submetidas à utilização intensiva dos recursos naturais sem manejo técnico adequado. Sobre esse contexto, Sales (2003, p.02) acrescenta com propriedade que:

A pressão da população sobre os recursos naturais, já naturalmente frágeis, leva à deterioração ambiental gerando um ciclo de pobreza e miséria, tornando a região cada vez mais vulnerável. A vulnerabilidade neste caso é resultado da fragilidade ambiental, econômica e social, constituindo-se em um imbricado processo de retroalimentação.

No caso da bacia hidrográfica em questão, a degradação ambiental torna-se preocupante nas áreas de maior fragilidade potencial, nas quais as condições ecológicas impedem ou dificultam a regeneração da cobertura vegetal quando surge uma oportunidade para o reestabelecimento de seu tênue equilíbrio. Conforme observado, essas manchas de maior instabilidade ambiental perfazem os municípios do núcleo de desertificação do Seridó. Áreas essas que, segundo Vasconcelos Sobrinho (1971), caracterizariam-se em condição de irreversibilidade, reflexo da excessiva pressão antrópica sobre os recursos naturais.

Sobre essa assertiva, pelos próprios aspectos morfopedológicos e/ou ainda pela fitofisionomia da cobertura vegetal de Caatinga, esses mesmos ambientes revelam-se instáveis, favorecendo e/ou potencializando os processos erosivos através dos quais o fenômeno da desertificação se intensifica e se retroalimenta. Segundo acrescentam Geist e Lambin (2004), entender os padrões regionais da desertificação através da sinergia entre os fatores causais, compõe, portanto, as vias específicas para intervenções políticas adequadas e eficientes.

Ab'Saber (1977, p. 02) descreve ainda como processos parciais de desertificação: "todos aqueles fatos pontuais ou areolares suficientemente radicais para criar degradações irreversíveis da paisagem e dos tecidos ecológicos naturais”. Além disso, conforme acrescenta o referido autor (op. cit, p. 07), em todos os casos, "as degradações mais graves são exatamente aquelas que atingem a própria funcionalidade dos ecossistemas regionais [...]", com exemplo à ocorrência de erosão laminar excessiva e presença de ravinamentos. Contexto esse encontrado neste trabalho sobre as áreas de forte fragilidade ambiental.

No que diz respeito à bacia hidrográfica do Rio Seridó (RN/PB), segundo acrescenta Duque (1953, p.45), ainda em meados da década de 1950, essa é a região "mais erodida do Nordeste"; de modo a já "não mais existir solo nas colinas e as árvores e os arbustos se localizam muito distanciados pela dificuldade de enraizamento". Esse é um contexto que pode e deve ser melhor entendido com a análise da fragilidade ambiental em questão, ao apontar e identificar as áreas de maior instabilidade então existentes.

Destarte, o semiárido brasileiro destaca-se pela instabilidade de seu equilíbrio ecológico, condicionando, em associação à histórica e excessiva degradação ambiental, uma vocação e possibilidade para o estabelecimento e instalação do fenômeno da desertificação. Nesse caso, a fragilidade natural propicia que o surgimento ou desenvolvimento de áreas degradadas evoluam de tal modo que se transformem em núcleos de desertificação (AB'SABER, 1977; SALES, 2003; NASCIMENTO, 2006; PEREIRA NETO, 2013). Para Hare et al. (1992), ao menos que sejam tomadas medidas preventivas, seja talvez ainda mais frequente se verificar que este fenômeno avance de modo auto-acelerado e em retroalimentação.

\section{Considerações Finais}

O relevo exerce importante influência no contexto da análise ecodinâmica e da indicação da estabilidade ou instabilidade do meio, em associação às condições pedológicas e climáticas (fragilidade potencial); de modo ainda combinados com o grau de degradação ou conservação da cobertura vegetal (fragilidade emergente).

A identificação das diferentes fragilidades das bacias hidrográficas da região semiárida brasileira e, em especial, da bacia hidrográfica do Rio Seridó (RN/ PB) revela-se, portanto, como elemento-chave para a identificação de áreas potencialmente instáveis que, sob o contexto socioambiental inserido, é de fundamental importância para o entendimento do fenômeno da desertificação. Torna-se, portanto, uma ferramenta ímpar para o estabelecimento de alternativas ou de restrições com relação ao processo de apropriação da paisagem.

O estabelecimento de ações conservacionistas ou de recuperação de áreas potencialmente instáveis/ estáveis, tende a refletir no melhoramento da qualidade 
de vida humana e na conservação dos recursos naturais, conforme a complexidade e fragilidade dos sistemas geoambientais da bacia hidrográfica do Seridó e em todo o semiárido brasileiro.

Destarte, a realização de outros estudos que aprofundem essa problemática são, portanto, de relevância fundamental para o entendimento de todo o contexto geoambiental envolvido com os diferentes fluxos de matéria e energia.

\section{Referências Bibliográficas}

AB'SABER, A. N. O domínio morfoclimático semiárido das Caatingas brasileiras. Geomorfologia, São Paulo, n. 43, p. $1-3,1974$.

AB'SABER, A. N. Problemática da desertificação e da savanização no Brasil intertropical. Geomorfologia, São Paulo, n. 53, p. 1-20, 1977.

AB'SABER, A. N. Os domínios de natureza no Brasil: potencialidades paisagísticas. 4. ed. São Paulo: Ateliê Editorial, 2007.

ADEEL, Z.; SAFRIEL, D. NIEMEIJER; WHITE, R. Ecosystems and human well-being: Desertification synthesis. Washington, DC: World Resources Institute, 2005.

ALVES, J. J. Caatinga do Cariri paraibano. Revista Geonomos, v. 17, n.1, p.: 19-25, 2009.

ALVES, J. J. Geoecologia da Caatinga no Semi-árido do Nordeste brasileiro. Climatologia e Estudos da Paisagem. Rio Claro, v..2, n.1, p. 58-71,2007

ANDRADE-LIMA, D. The caatingas dominium. Revista Brasileira de Botânica,v. 4, n. 2, p. 149-163, 1981.

AZEVEDO, F. F. de. Environment degrading agents at the brazilian northeast: a study of case at the Seridó potiguar region. Revista Sociedade \& Natureza, Uberlândia, edição especial, v. 1, n1, p. 636-642, maio, 2005.

BERTONI, J.; LOMBARDI NETO, F. Conservação do solo. 8. ed. São Paulo: Editora Ícone, 2012.

BOTELHO, R. G. M.; SILVA, A. S. S. Bacia Hidrográfica e Qualidade Ambiental. In: VITTE, A. C.; GUERRA, A. J. T. (Orgs.). Reflexões sobre a Geografia Física no Brasil. 2. ed. Rio de Janeiro: Bertrand Brasil, 2011.

BRASIL. Ministério das Minas e Energia. Projeto Radam Brasil. Rio de Janeiro, RJ, 1981, 744 p.
BRASIL. Ministério do Meio Ambiente (MMA). Programa de ação nacional de combate à desertificação e mitigação dos efeitos da seca - PAN/BRASIL. Brasília: MMA, 2004.

CARVALHO, A. E. GARIGLIO, M. A.; BARCELLOS, N. D. E. Caracterização das áreas de ocorrência de desertificação no Rio Grande do Norte: [s.n.], Natal, 2000.

COELLHO NETO, A. L. Hidrologia de encosta na interface com a Geomorfologia. In: GUERRA, A. J. T.; CUNHA, S. B. (Orgs.). Geomorfologia: uma atualização de bases e conceitos. 2. ed. Rio de Janeiro: Bertrand Brasil, 2007.

CHRISTOFOLETTI, A. Geomorfologia. São Paulo: Edgard Blücher, Ed. Da Universidade de São Paulo (USP), 1974.

CHRISTOFOLETTI, A. Modelagem de Sistemas Ambientais. São Paulo: Edgar Blücher ltda, 1999.

CREPANI, E; MEDEIROS, J. S. de; HERNANDEZ FILHO, P.; FLORENZANO, T. Gallotti; DUARTE V.; BARBOSA, C. C. F. Sensoriamento remoto e geoprocessamento aplicados ao zoneamento ecológico econômico e ao ordenamento territorial. São José dos Campos: SAE/INPE, 2001.

DUQUE, J. G. Solo e água no polígono das secas. 3. ed. Fortaleza: Departamento Nacional de Obras contra as Secas (DNOCS), 1953.

DUQUE, J. G. O Nordeste e as lavouras xerófilas. Fortaleza: Banco do Nordeste do Brasil, 1964.

GEIST, H. J.; LAMBIN, E. F. Dynamic Causal Patterns of Desertification. Journal BioScience, v.54, n. 9, p. 817-829, 2004.

GOMES, A. R.; CREPANI, E.; CARVALHO, V. C. de; MEDEIROS, J. S. de. Aplicação da metodologia ZEE para a análise da vulnerabilidade à perda de solo em ambiente semiárido. In: SIMPÓSIO BRASILEIRO DE SENSORIAMENTO REMOTO, 12., Goiânia. Anais...Goiânia: INPE, 2005, p. 3519-3526.

HARE, F. K.; WARREN, A.; MAIZELS, J. K.; KATES, R. W.; JOHNSON, D. L.; HARING, K. J.; GARDUÑO, M. A. Desertificação: causas e consequências. Lisboa: Fundação Calouste Gulbenkian, 1992.

HERRMANN, S. M.; HUTCHINSON, C. F. The changing contexts of the desertification debate. Journal of Arid Environments, v.63, n. 3, p.538-555, 2005.

HOWARD, A. D. Equilibrium models in geomorphology. In: ANDERSON, M. G. (Org.). Modelling Geomorphological Systems. Chichester: John Wiley \& Sons, 1988. 
JACOMINE, P. K. T.; RODRIGUES E SILVA, F. B.; FORMIGA, R. A.; ALMEIDA, J. C.; BELTRÃO, V. A.; PESSÔA, S. C. P.; FEREIRA, R. C. Levantamento exploratório - reconhecimento de solos do estado do Rio Grande do Norte. Recife: Ministério da Agricultura/Sudene, 1971.

JACOMINE, P. K. T.; RIBEIRO, M. R.; MONTENEGRO, J. O.; SILVA, A. P.; MÉLO FILHO, H. F. R. Levantamento exploratório - reconhecimento de solos do estado da Paraíba. Rio de Janeiro: Ministério da Agricultura/Sudene, 1972. MEDEIROS, J. D. F. et al. Análise da precipitação e do escoamento superficial na bacia hidrográfica do rio PiranhasAçu/RN. Natal - RN: EMPARN, 2005.

MOLLE, F. Planning and managing water resource sat the river-basin level: emergence an devolution of a concept. Colombo, Sri Lanka: International Water Magement Institute, 2006.

MOLINIER, M. ALBUQUERQUE C. de; CADIER, E. Análise da pluviometria e isoietas homogeneizadas do Nordeste Brasileiro. Recife: SUDENE, DPG, PRN, HME, 1994.

MORAIS, L. J.; BARROS, F. C. Reconhecimento fotogeológico da região Nordeste do Brasil: folhas de Currais Novos, Caicó e Orós. Rio de Janeiro: MME/DNPM, 1960.

NASCIMENTO, F. R. Degradação ambiental e desertificação no Nordeste brasileiro: o contexto da bacia do Rio Acaraú - Ceará. 2006. 324 f. Tese (Doutorado em Geografia) Universidade Federal Fluminense (UFF), Niterói, 2006.

PEREIRA NETO, M. C. Fragilidade ambiental da bacia hidrográfica do Rio Seridó (RN/PB - Brasil). 2013. 117 f. Dissertação (Mestrado em Geografia). Universidade Federal do Rio Grande do Norte, Natal/RN, 2013.

PEREIRA NETO, M. C; SILVA, N. M. Relevos residuais (maciços, inselbergues e cristas) como refúgios da biodiversidade no Seridó potiguar. Revista GEONORTE, edição especial, v.1, n.4, p. 262-273, 2012.

RIO GRANDE DO NORTE (Estado). PDSS - Plano de Desenvolvimento Sustentável do Seridó. Natal: IICA, 2000 (2 volumes).
ROSS, J. L. S. Geomorfologia, ambiente e planejamento. São Paulo: Contexto, 1990. 88 p.

ROSS, J. L. S. Análise empírica da fragilidade dos ambientes naturais e antropizados. Revista do Departamento de Geografia, São Paulo, n. 8, p. 24-30, 1994.

SALES, M. C. L. Evolução dos estudos de desertificação no nordeste brasileiro. Revista GEOUSP - Espaço e Tempo, São Paulo, n. 14, p. 9-19, 2003.

SOUZA, M. J. N.; OLIVEIRA, V. P. V. Análise ambiental uma prática da Interdisciplinaridade no ensino e na pesquisa. REDE - Revista Eletrônica do Prodema, Fortaleza, v. 7, n.2, p. 42-59, 2011.

SILVA, F. H. B. SILVA, F. H. B. B da; BURGOS, N.; ACCIOLY, L. J. de O.; COSTA, T. C. C. da; OLIVEIRA, M. A. J. de. Caracterização dos recursos naturais de uma área piloto do núcleo de desertificação do Seridó, estados do Rio Grande do Norte e da Paraíba. Rio de Janeiro: Embrapa Solos, 2002.

SPÖRL, C. Análise da fragilidade ambiental relevo-solo com aplicação de três modelos alternativos nas altas bacias do Rio Jaguari-Mirim, Ribeirão do Quartel e Ribeirão da Prata. 2001. 159 f. Dissertação (Mestrado em Geografia Física) - Universidade de São Paulo, São Paulo, 2001.

SPÖRL, C.; ROSS, J. L. S. Análise comparativa da fragilidade ambiental com aplicação de três modelos. GEOUSP: Espaço e Tempo, São Paulo, v., 15, n. 15, p. 39-49, 2004.

TRICART, J. Ecodinâmica. Rio de Janeiro, IBGE/SUPREN, 97 p. 1977.

TRICART, J.; KILIAN. J. L'écogéographie et l’aménagement du milieu naturel. Paris: François Maspero, 1979.

VALADÃO, C. E. A.; OLIVEIRA, P. T.; SCHMIDT, D. M.; SILVA, B. K. N; BARRETO, N. J.C.; CORREIA FILHO, W. L. F.; JESUS, E. S.; LOPO, B. A.; SANTOS, A.; PINHEIRO S. J. U.; MATTOS, A. Classificação climática da Microrregião do Seridó/RN. Congresso Brasileiro de Meteorologia, XVI edição, Belém/PA. Anais... Belém: Sociedade Brasileira de Meteorologia. Disponível em: cbmet2010.web437.uni5.net/ anais/artigos/584_23902.pdf. Acesso em 20 de nov. 2013. 